\title{
Circadian Timekeeping in BALB/C and C57BL/6 Inbred Mouse Strains
}

\author{
William J. Schwartz and Pamela Zimmerman \\ Department of Neurology, University of Massachusetts Medical School, Worcester, Massachusetts 01655
}

\begin{abstract}
Circadian rhythms of locomotion (wheel-running activity) In 12 inbred mouse strains were recorded for interstrain differences in $\tau_{D D}$, the endogenous (free-running) period of the circadian pacemaker measured in constant environmental darkness. The results indicate that 1 or more genetic loci influence the value of $\tau_{\mathrm{DD}}$, and a large $(50 \mathrm{~min})$ difference in mean $\tau_{\text {DD }}$ between 2 of the strains, BALB/CByJ and C57BL/ $6 \mathrm{~J}$, allowed further characterization of the origins and inheritance of the polymorphic expression of this circadian pacemaker property. The interstrain difference in mean $\tau_{D D}$ was associated with an interstrain difference in light-induced shifts of the phase of the free-running locomotor rhythm; the BALB/C strain (with the shorter mean $\tau_{\mathrm{DD}}$ ) displayed relatively fewer advance phase shifts. Neither the history of previous light exposure, albinism, nor elevated circulating testosterone levels could account for the interstrain difference in mean $\tau_{\mathrm{DD}}$. The value of $\tau_{\mathrm{DD}}$ based on the clrcadian rhythm of drinking activity (with the running wheel removed) was longer than that based on locomotion; this discrepancy was significantly greater and more variable in BALB/C than in C57BL/ 6 mice, though the interstrain difference in mean $\tau_{D D}$ could not be attributed entirely to this effect. Reciprocal $F_{1}$ hybrids of BALB/C $\times$ C57BL/ 6 matings revealed dominance of the C57BL/ 6 genotype, no sex linkage, and a significant (but small) maternal effect. Examination of $\mathrm{CXB}$ recombinant inbred strains provided no support for the hypothesis of monogenic inheritance. Further study of inherited differences in the BALB/C and C57BL/6 strains may be a useful noninvasive experimental approach for investigation of the neurobiological substrates of circadian rhythmicity.
\end{abstract}

Daily rhythms of the biological activities in plants and animals are well-cataloged, universal phenomena. Ordinarily, environmental light synchronizes (entrains) the period and phase of these rhythms to the natural day-night cycle; but even in the absence of periodic environmental timing cues, many rhythms continue to oscillate (free run) with approximate 24-hr (circadian) periods. The persistence and properties of such environmentally independent, self-sustaining rhythms suggest the ex-

\footnotetext{
Received Apr. 3, 1990; revised June 25, 1990; accepted July 5, 1990.

We gratefully thank Drs. Karen Pettigrew and Robert Lew for the statistical analyses, Dr. James Hamos for help with the image processing. Dr. Lawrence Recht for the computer-generated figures, Dr. Bernard Possidente for critical comments on the manuscript, Caroline Coletti and Lisa Davis for excellent technical assistance, and Eileen Staples for her patient secretarial work. W.J.S. is supported by NINDS R01 NS24542.

Correspondence should be addressed to William J. Schwartz, Department of Neurology, University of Massachusetts Medical School, 55 Lake Avenue North, Worcester, MA 01655

Copyright (C) 1990 Society for Neuroscience $0270-6474 / 90 / 113685-10 \$ 03.00 / 0$
}

istence of an innate timekeeping mechanism, that is, a "biological clock" (Aschoff, 1981). Discrete neural sites that contain such clocks have now been identified in the nervous systems of a number of organisms. In mammals, such a pacemaker has been localized to the suprachiasmatic nuclei (SCN) of the anterior hypothalamus (for review, see Meijer and Rietveld, 1989): (1) lesions of the SCN result in a breakdown of the entrainment or generation of a wide array of behavioral, physiological, and endocrinological circadian rhythms (Moore, 1981); (2) electrical (Rusak and Groos, 1982) and pharmacological (Zatz and Herkenham, 1981; Earnest and Turek, 1985) stimulation of the nuclei causes predictable phase shifts of such thythms; (3) SCN energy metabolism (Schwartz et al., 1980; Newman and Hospod, 1986), electrical activity (Inouye and Kawamura, 1979; Green and Gillette, 1982; Shibata et al., 1982), and vasopressin secretion (Schwartz and Reppert, 1985; Earnest and Sladek, 1986) all exhibit circadian rhythmicity in vivo and in vitro; and (4) neural grafts of fetal SCN tissue reestablish overt rhythmicity in arrhythmic, SCN-lesioned recipients (Sawaki et al., 1984; Aguilar-Roblero et al., 1986; Lehman et al., 1987; DeCoursey and Buggy, 1989), and the rhythms restored by the transplants display properties that are characteristic of the circadian pacemakers of the donors rather than those of the hosts (Earnest et al., 1989; Ralph et al., 1990). Present research is now exploiting these kinds of techniques to elucidate the cellular and molecular proccsses that constitute the SCN's actual timekeeping machinery.

Another tactic for investigating clock function without the interference of lesions, drugs, or invasive methodologies is to look for genetic variation of circadian pacemaker properties. The techniques of induced mutagenesis and modern molecular genetics have yielded remarkable results identifying genetic loci that affect pacemaker behavior in Drosophila and Neurospora (for review, see Hall and Rosbash, 1987). "Clock mutations" in rodents are also known: there are congenitally anophthalmic rats (Richter, 1971; Ibuka, 1987) and mice (Scheuch et al., 1982; Gattermann et al., 1987) that do not entrain to light-dark (LD) cycles, mice with hypogenesis of the SCN that show disorganized circadian locomotor rhythmicity (Scheuch et al., 1982; Noguchi et al., 1986), mice that do not synthesize pineal melatonin (Ebihara et al., 1987), and golden hamsters with a mutation that shortens their pacemaker's free-running circadian period (Ralph and Menaker, 1988). Natural genetic differences (polymorphisms) manifested by inbred strains of rodents also suggest that genetic background affects circadian rhythmicity (e.g., Ebihara et al., 1978; Oliverio and Malorni, 1979; Possidente and Hegmann, 1980; Connolly and Lynch, 1981; Peleg et al., 1982; Büttner and Wollnik, 1984; Beau, 1988), but more work is needed in this area. Some of these studies were conducted in the presence of LD cycles, so free-running circadian rhythmicity 
could not be assessed; some were performed in continuous environmental illumination, so effects on retinal photoreceptors could not be differentiated from effects on the circadian pacemaker itself; some compared small numbers of strains, so generalizations could not be confidently made; and some used inadequate or imprecise tools for measurement of circadian pacemaker properties.

In this paper, we report our survey of 12 inbred mouse strains for interstrain differences in $\tau_{D D}$, the free-running period of the circadian pacemaker measured in constant environmental darkness. The circadian rhythm we recorded was locomotor activity in a running wheel; the onset of this activity is precise, and the rhythm has already been extensively analyzed (Pittendrigh and Daan, 1976a). Two strains that expressed a large difference in $\tau_{\mathrm{DD}}, \mathrm{BALB} / \mathrm{c}$ and $\mathrm{C} 57 \mathrm{BL} / 6$, were then chosen for further study. We characterized light-induced phase shifts of their free-running locomotor rhythms, investigated some of the potential origins of their inherited difference in $\tau_{\mathrm{DD}}$, and began to analyze the mode of inheritance of this difference. The goal of our experiments was to provide a foundation of basic information to encourage future physiological, pharmacological, and morphological studies of the circadian systems of thesc 2 widely utilized mouse strains.

\section{Materials and Methods}

Animals. Male mice, 4-6 weeks old at time of delivery, were obtained from the Jackson Laboratory, Bar Harbor, ME, or, in some instances, males and females were mated in our facility. Animals were individually housed in clear polycarbonate cages $\left(19 \times 10^{1 / 2} \times 8^{\prime \prime}\right)$ contained within well-ventilated, light-proof environmental compartments (12 cages/ compartment, 4 shelves of 3 cages each) isolated in an animal facility with temperature thermostatically controlled. Strains were not routinely segregated by shelf or compartment. Plastic cage bottoms were cut out and replaced by stainless-steel wire mesh (Fenco Cage Products, Boston, MA), so that the cages could be suspended over trays containing wood shavings and chlorophyll pellets. Trays were cleaned and food hoppers and water bottles refilled once every 3 weeks without handling the animals. Light was provided by $15-\mathrm{W}$ cool-white fluorescent tubes mounted above the shelves; intensity varied within the cages but was on the order of $300-400$ lux at the midcage level. No light was present during darkness. When necessary, a single $15-\mathrm{W}$ safe light with a dark red (series 2) filter was used to allow for routine care; mice were exposed to approximately 30 lux maximally and $<1$ lux usually.

Behavioral assays. Locomotor activity was monitored in mice when they were from 8 to 12 weeks old. A microswitch on the outside of each cage was activated by the rotation of a $5^{\prime \prime}$ metal running wheel. The number of switch closures per $15-\mathrm{min}$ interval was automatically recorded and stored on hard disk by an IBM computer-based data-acquisition system (Dataquest, Mini-Mitter, Sunriver, OR). After log transformation, the number of wheel revolutions per 15-min interval was plotted for each mouse as an actogram; that is, activity over the course of each 24-hr period was plotted horizontally from left to right, with succeeding days stacked vertically from top to bottom. "Doubleplotted" actograms repeated this format for 48-hr periods; that is, day $n$ was followed by day $n+1$ horizontally, succeeded by day $n+1$ and $n+2$ on the next line, then by day $n+2$ and $n+3$, and so on.

Drinking activity was monitored in similarly aged animals housed in the same cages but with the running wheels removed. Leads from false, raised cage floors constructed from 20-gauge galvanized-steel wire cloth (Hub Wire Cloth, Everett, MA) and from the metal spouts of drinking tubes were wired to lick sensors so that each tube contact was recorded and stored by the computer. After log transformation, the number of licks per 15-min interval was plotted in actogram format.

All mice were entrained to a 12-hr: 12-hr LD cycle for 10-14 d before exposure to constant darkness for an additional $2-4$ weeks. $\tau_{D D}$ was calculated from the slope of a visually fit line through successive daily activity onsets (Pittendrigh and Daan, 1976a) and reported as mean \pm SEM. Each of the experiments further characterizing the BALB/c and C57BL/6 strains was conducted using new sets of purchased mice; the
2 strains or treatments to be compared were run concurrently in the same cabinets.

Procedures. Phase-response curves (PRCs) were constructed using a population of 8 mice from each of the BALB/c and C $57 \mathrm{BL} / 6$ strains; 2 mice, 1 animal from each strain, were individually housed per shelf on 8 shelves. Animals free-running in constant darkness were exposed to a succession of single light pulses (100-200 lux for $15 \mathrm{~min}$ ), 1 pulse every 2 weeks. The phase of the circadian cycle upon which the light fell was calculated afterwards for each animal and expressed as circadian time (ct), where ct 12 - the time of expected onset of locomotor activity and 1 circadian hour $=\tau_{\mathrm{DD}} / 24 \mathrm{hr}$. Light-induced phase shifts of the locomotor rhythm were measured by subtracting the new phase of activity onset (after transients had subsided) from the predicted phase of activity onset, as extrapolated from the $\tau_{\mathrm{DD}}$ immediately preceding the light pulse. Therefore, negative values represented phase delays, and positive values represented phase advances. In order to plot a composite PRC for animals with differing $\tau_{\mathrm{DD}} \mathrm{s}$, phase shifts were normalized into degrees of arc by multiplying each shift in $\mathrm{hr}$ by the factor $360 \% \tau_{\mathrm{DD}}$ (Daan and Pittendrigh, 1976a). Data were collected and plotted in bins 2 circadian $\mathrm{hr}$ wide. Area measurements [in degrees of arc $\times$ hr $\left({ }^{\circ} \mathrm{hr}\right)$ ] were made on a Zeiss (Kontron) IBAS 2000 image processing system.

Orchiectomies were performed on mice anesthetized with pentobarbital $(50 \mathrm{mg} / \mathrm{kg}$, i.p.) and treated with atropine sulfate $(0.25 \mathrm{mg} / \mathrm{kg}$, i.m.). The scrotum was opened along the midline, vas deferens tied, and testicles removed. Sham-operated animals received horizontal, low abdominal incisions only.

\section{Results}

Table 1 shows mean values of $\tau_{D D}$ for locomotor rhythms in the 12 inbred mouse strains we surveyed. The range of values was large (nearly $1 \mathrm{hr}$, from 22.94 to $23.93 \mathrm{hr}$ ), with a grand mean $\tau_{\mathrm{DD}}$ of $23.53 \mathrm{hr}$ for all the strains combined. Variability within the strains was not homogeneous across the 12 strains $[p<0.05$, Levene's test for variances; $F=2.07 ; d f=(11,60)]$. An analysis of variance (ANOVA) comparing the variability between strains to the variability within strains (Welch approximation for unequal variances) showed that the 12 strain means were not homogeneous $[p<0.0001 ; F=26.62, d f=(11,19)]$. These tests indicate that the interstrain variation of $\tau_{D D}$ was significantly greater than its intrastrain variation.

We chose the BALB/cByJ and $\mathrm{C} 57 \mathrm{BL} / 6 \mathrm{~J}$ strains to further investigate these interstrain differences. Their mean $\tau_{\mathrm{DD}}$ difference of $0.83 \mathrm{hr}$ (nearly $50 \mathrm{~min}$ ) $(p<0.001$, pairwise $t$ test with Bonferroni correction) was easily seen on actograms with the naked eye (Fig. 1) and represented nearly the full range of short and long $\tau_{\mathrm{DD}}$ 's that we measured. Additional advantages to the choice of these 2 strains were their ready availability and low expense, the existence of recombinant inbred (RI) strains (see below), and their widespread use in a variety of biomedical research applications (Foster et al., 1982).

\section{Light-induced phase shifts of locomotor rhythms in $B A L B / C$ and C57BL/6 strains}

Despite the gross interstrain difference in mean $\tau_{\mathrm{DD}}$, onset of locomotor activity in both strains began at or near the onset of darkness when animals were maintained in a 12-hr:12-hr LD cycle (Fig. 1). In some of the BALB/c mice, this observed phase of activity onset was not the phase predicted by backward extrapolation along the slope of onsets during the subsequent free run in constant darkness (e.g., Fig. 1, left), suggesting that earlier activity onset might be "masked" by the light phase of the LD cycle. This was not a consistent finding, however, and activity onset after lights out in other BALB/c mice appeared to reflect true entrainment. Because the phase relationship of an entrained circadian rhythm to the LD cycle is a function of both $\tau$ and light-induced phase shifts of the circadian pacemaker's endog- 
Table 1. $\tau_{\mathrm{DD}}$ of inbred mouse strains

\begin{tabular}{lrl} 
Strain & $n$ & Mean $\tau_{\mathrm{DD}} \pm$ SEM \\
\hline $129 / \mathrm{J}^{a}$ & 6 & $23.93 \pm 0.07$ \\
$\mathrm{RF} / \mathrm{J}^{a}$ & 6 & $23.92 \pm 0.06$ \\
$\mathrm{C} 57 \mathrm{BL} / 6 \mathrm{~J}$ & 10 & $23.77 \pm 0.02$ \\
$\mathrm{SWR} / \mathrm{J}^{a}$ & 3 & $23.70 \pm 0.02$ \\
$\mathrm{SEC} / 1 \mathrm{ReJ}$ & 8 & $23.59 \pm 0.04$ \\
$\mathrm{AKR} / \mathrm{J}^{a}$ & 5 & $23.52 \pm 0.04$ \\
$\mathrm{DBA} / 2 \mathrm{~J}$ & 3 & $23.46 \pm 0.05$ \\
$\mathrm{C} 57 \mathrm{BL} / 10 \mathrm{~J}$ & 5 & $23.43 \pm 0.01$ \\
$\mathrm{C} 57 \mathrm{~L} / \mathrm{J}$ & 4 & $23.42 \pm 0.13$ \\
$\mathrm{~A} / \mathrm{J}^{a}$ & 10 & $23.37 \pm 0.07$ \\
$\mathrm{~B} 10 . \mathrm{D} 2(58 \mathrm{~N}) / \mathrm{Sn}$ & 4 & $23.34 \pm 0.15$ \\
$\mathrm{BALB} / \mathrm{cByJ}{ }^{a}$ & 8 & $22.94 \pm 0.06$
\end{tabular}

${ }^{a}$ Albino strains.

enous oscillation (Pittendrigh and Daan, 1976b), the BALB/c and $\mathrm{C} 57 \mathrm{BL} / 6$ pacemakers or their input pathways must differ in their response to light. We quantified this difference by constructing PRCs for the 2 strains, that is, by plotting the phase shifts that occurred in their locomotor rhythms when light was applied at different phase points across the free-running circadian cycle (Fig. 2). The plots for the 2 strains were similar to each other and exhibited the familiar features of circadian PRCs (Fig. 3). Light pulses around the onset of locomotor activity (early subjective night) delayed the succeeding activity rhythm, whereas pulses near activity offset (late subjective night) caused a phase advance. Pulses presented during inactivity (subjective day) had little or no effect. For both strains, the area under the delay part of the curve $(D)$ was considerably greater than that under the advance part $(A): D$ was twice the value of $A$ in C57BL/6 mice $\left(D, 205^{\circ} \mathrm{hr} ; A, 97^{\circ} \mathrm{hr}\right)$ and 4 times the value of $A$ in BALB/c mice $\left(D, 164^{\circ} \mathrm{hr} ; A, 42^{\circ} \mathrm{hr}\right)$. The 2 PRCs were essentially indistinguishable except for phase points during the late subjective night-early subjective day (ct 22 to ct 2); at these times, no phase advances were observed in BALB/c mice. $D$ in the $\mathrm{BALB} / \mathrm{c}$ strain was $80 \%$ of the value of $D$ in the $\mathrm{C} 57 \mathrm{BL} / 6$ strain, but $A$ in BALB/c was only $43 \%$ of the value of $A$ in C57BL/6. Therefore, when $A$ is subtracted from $D[D-A$, an expression of PRC shape (Daan and Pittendrigh, 1976a)], the result is larger in the $\mathrm{BALB} / \mathrm{c}$ strain with its relatively short mean $\tau_{\mathrm{DD}}\left(122^{\circ} \mathrm{hr}\right)$ than in the C57BL/6 strain with its relatively long mean $\tau_{\mathrm{DD}}\left(108^{\circ} \mathrm{hr}\right)$.

\section{On the origins of the $B A L B / C$ and $C 57 B L / 6$ inherited strain difference in mean $\tau_{D D}$}

The value of $\tau$ is influenced by the parameters of the preceding entrainment schedule, that is, the LD cycle's period and photoperiod, and by the history of previous light pulses (Pittendrigh and Daan, 1976a). Although BALB/c and C57BL/6 mice were both entrained to the same 12-hr:12-hr LD cycle for 10-14 d beforc $\tau_{\text {DD }}$ was measured, we could not be certain how the animals were treated before they were shipped to us. In order to determine whether unsuspected aftereffects of previous light exposure might account for the interstrain difference in mean $\tau_{\mathrm{DD}}$, $\mathrm{BALB} / \mathrm{c}$ and $\mathrm{C} 57 \mathrm{BL} / 6$ mice were raised in darkness from conception through birth, weaning, and behavioral testing. Male and female mice of each strain were housed together until a vaginal plug was observed; impregnated females ( $2 \mathrm{BALB} / \mathrm{c}$ and $3 \mathrm{C} 57 \mathrm{BL} / 6$ ) were maintained in constant darkness through pregnancy, parturition, and lactation; and pups from all litters were weaned in darkness at 4 weeks and placed in running-wheel cages at 5-6 weeks. Mean values of $\tau_{\mathrm{DD}}$ for locomotor rhythms in these BALB/c and C57BL/6 mice were $22.98 \pm 0.06 \mathrm{hr}(n$ $=8)$ and $23.77 \pm 0.04 \mathrm{hr}(n=11)$, respectively (Fig. 4); these values were clearly no different ( $p>0.6$ by ANOVA) from the values listed in Table 1 for mice that were previously entrained to an $L D$ cycle before $\tau_{\mathrm{DD}}$ was mcasurcd.

The value of $\tau$ for locomotor rhythmicity is reported to be longer in castrated male mice than in sham-operated controls (Daan et al., 1975); this effect is reversed by testosterone replacement. Interestingly, plasma testosterone levels in $\mathrm{BALB} / \mathrm{c}$ mice are reported to be twice the levels in C57BL/6 mice (Batty, 1978; Melanitou et al., 1987). In order to determine whether this interstrain endocrine difference might account for the shortened mean $\tau_{\mathrm{DD}}$ in the $\mathrm{BALB} / \mathrm{c}$ strain relative to the $\mathrm{C} 57 \mathrm{BL} / 6$ strain, male $B A L B / c$ mice underwent orchiectomy or sham operation. Animals were first maintained for 3 weeks in constant darkness, then placed in a 12-hr:12-hr LD cycle for $7 \mathrm{~d}$ before surgery, and, after an additional 7 postoperative $d$ in the LD cycle, they were reexposed to constant darkness. So that every

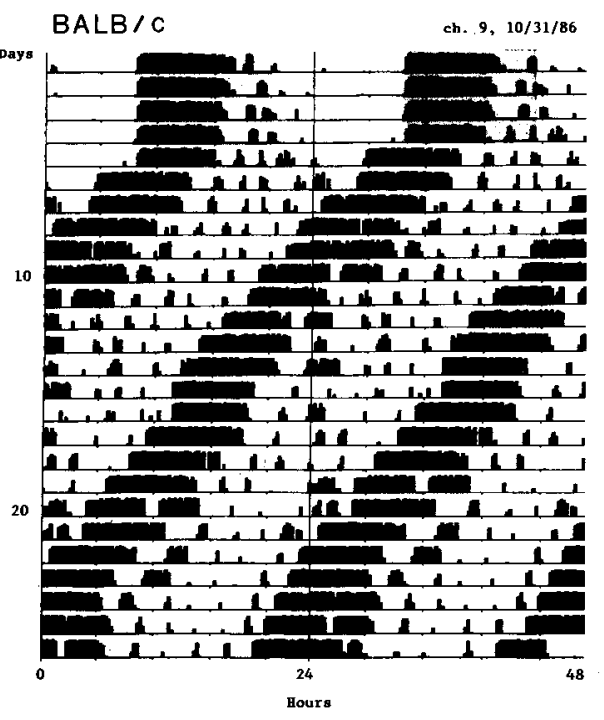

Figure 1. Double-plotted actograms of circadian locomotor rhythms in $\mathrm{BALB} / \mathrm{c}$ mouse (left) and $\mathrm{C} 57 \mathrm{BL} / 6$ mouse (right). The final $5 \mathrm{~d}$ of a $10-$ 14-d entrainment to a 12-hr:12-hr LD cycle are shown (the 12-hr dark phase is shaded), before the mice were placed in constant darkness. In these cases, $\tau_{\mathrm{DD}}$ was $22.88 \mathrm{hr}$ in the BALB/c mouse and $23.88 \mathrm{hr}$ in the C57BL/6 mouse. 
$B A L B / C$

\section{A. Subjective Day}

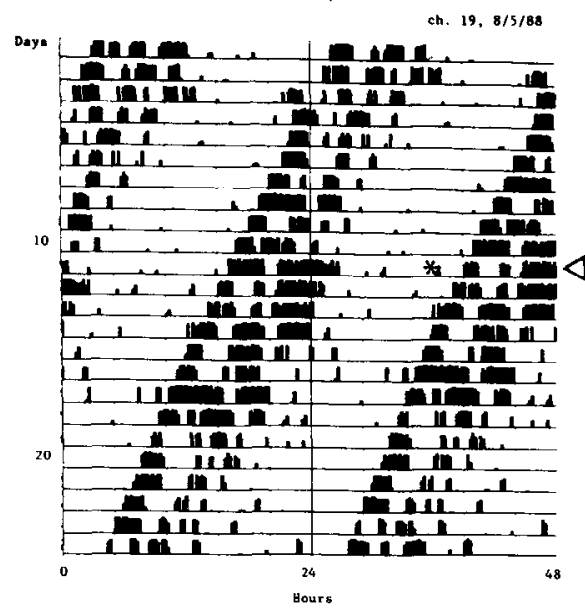

B. Early Subjective Night

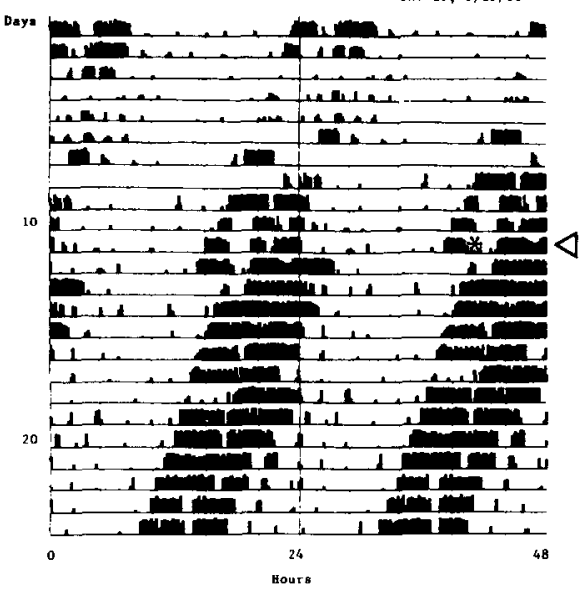

C. Late Subjective Night

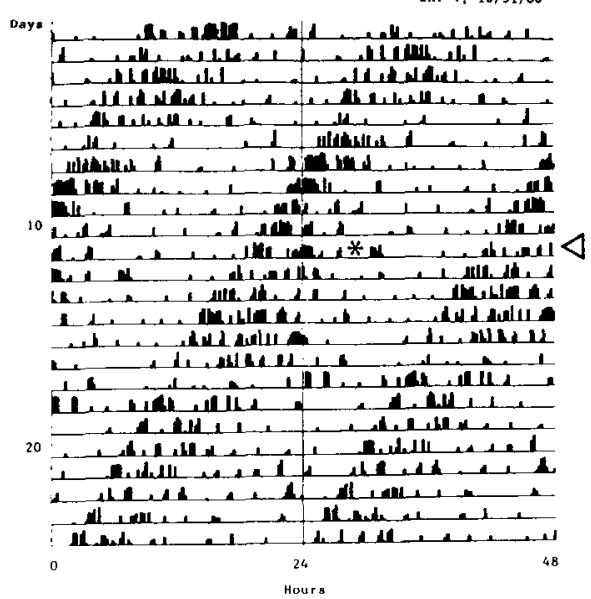

$\mathrm{C} 57 \mathrm{BL} / 6$
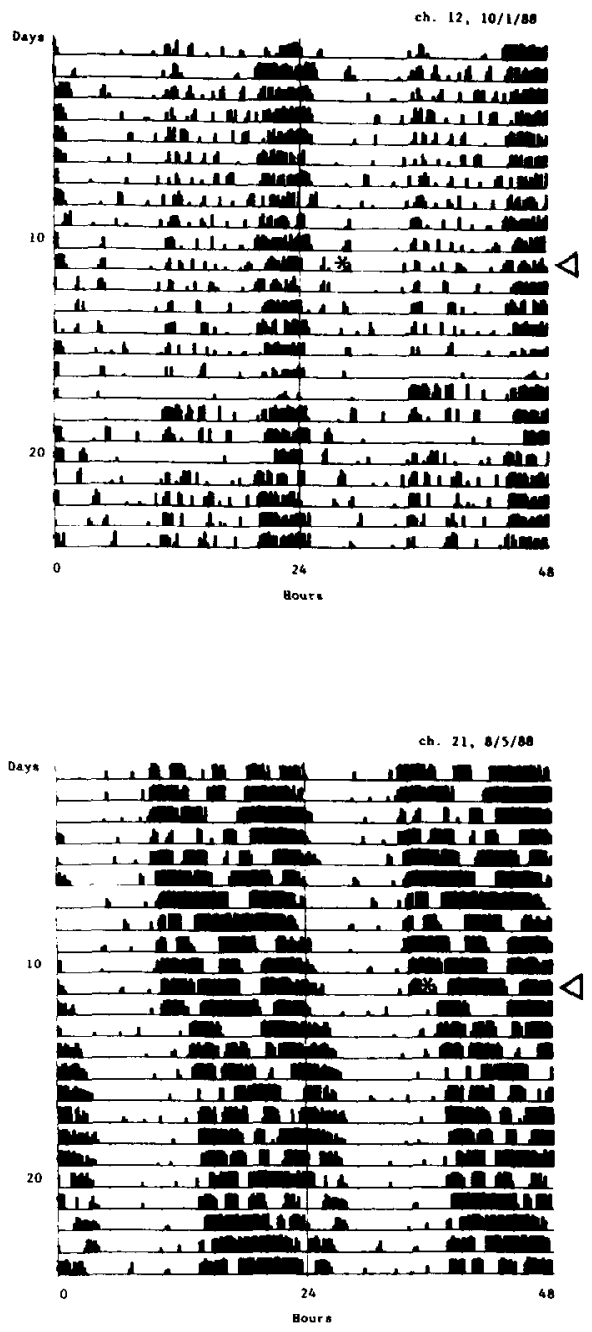

Figure 2. Light-induced phase shifts of free-running locomotor rhythms in $\mathrm{BALB} / \mathrm{c}($ left $)$ and $\mathrm{C} 57 \mathrm{BL} / 6$ (right) mice. Light pulses (100-200 lux for $15 \mathrm{~min}$ ) were applied on the days (open arrowheads) and times (asterisks) indicated. Pulses presented during inactivity (subjective day) had little or no effect (shown are ct 9 for $\mathrm{BALB} / \mathrm{c}$, ct 5 for $\mathrm{C} 57 \mathrm{BL}$ 6). Pulses near activity onset (early subjective night) caused phase delays (shown is ct 14 for both strains), whereas pulses near activity offset (late subjective night) caused phase advances in C57BL/6 mice only (shown are ct 24 for $\mathrm{BALB} / \mathrm{c}$ and $\mathrm{ct} 1$ for $\mathrm{C} 57 \mathrm{BL} / 6$ ). 


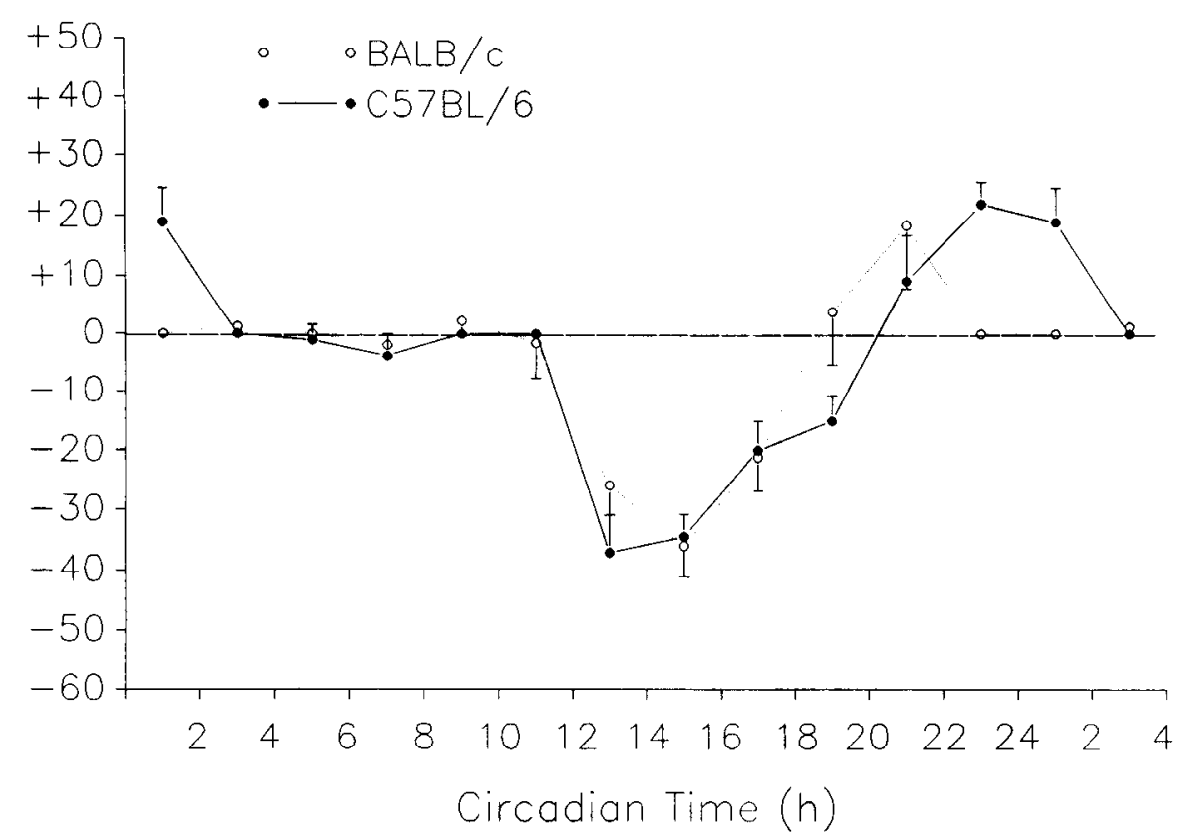

Figure 3. PRCs of 15-min light pulses in BALB/c and C57BL/6 mice. See Results for details. animal served as its own control, $\Delta \tau$ for each mouse was calculated by subtracting each animal's preoperative $\tau_{\mathrm{DD}}$ from its postoperative $\tau_{\mathrm{DD}}$. For most mice, $\Delta \tau$ had a positive value (i.e., castration lengthened $\tau_{\mathrm{DD}}$ by some amount); in 1 extraordinary animal, it increased from 22.72 to $23.50 \mathrm{hr}$ (a $\Delta \tau$ of $0.78 \mathrm{hr}$, nearly $47 \mathrm{~min}$; Fig. 5). However, the mean $\Delta \tau$ for the entire population of castrates was modest $(+0.19 \pm 0.10 \mathrm{hr}, n=8)$ and not significantly different from the mean $\Delta \tau$ for the population of sham-operated controls $[+0.04 \pm 0.06 \mathrm{hr}, n=6 ; p=$ 0.27 by ANOVA; $F=1.35, d f=(1,12)]$.

The value of $\tau$ is also modified by environmental influences; the use of a running wheel appears to shorten $\tau$ for activity rhythms in hamsters (Pratt and Goldman, 1986) and rats (Yamada et al., 1988). In order to determine whether an interstrain difference in the running wheel's $\tau$-shortening effect might ac-

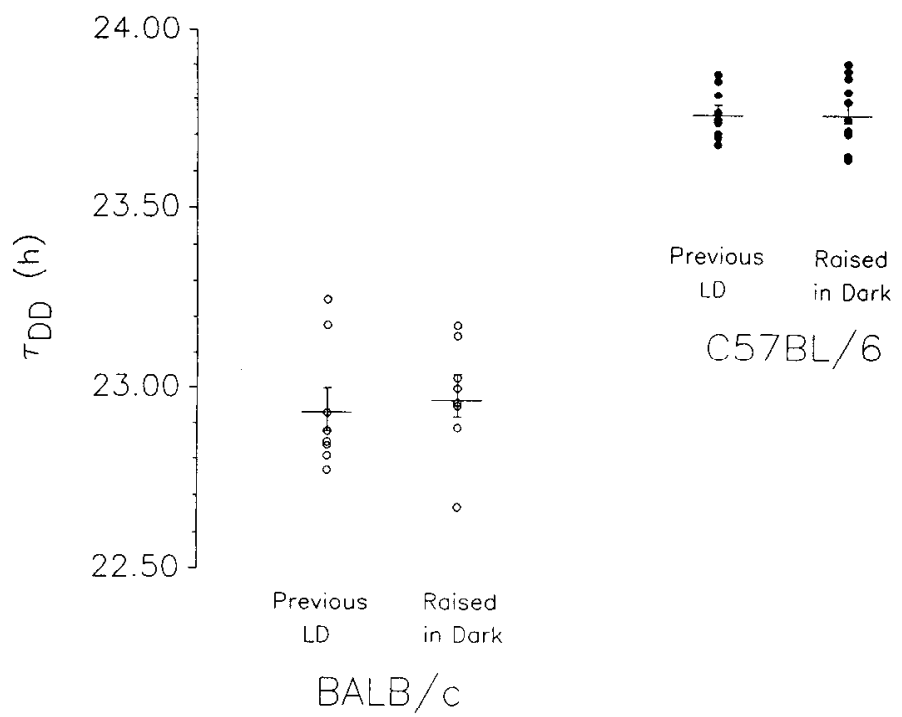

Figure 4. $\tau_{\mathrm{DD}}$ for locomotor rhythms in $\mathrm{BALB} / \mathrm{c}$ and $\mathrm{C} 57 \mathrm{BL} / 6$ mice after 10-14-d entrainment to 12-hr:12-hr LD cycle (from Table 1) and in mice raised in darkness from conception through birth, weaning, and behavioral testing. See Results for details. count for the interstrain difference in mean $\tau_{D D}$ that we measured, another circadian rhythm (drinking activity with the running wheel removed) was recorded in BALB/c and C57BL/6 mice. In 1 group of mice, locomotor activity was first recorded as usual in constant darkness, running wheels were then removed and the cages equipped for measuring drinking activity while the animals were maintained for $1-2$ weeks in a 12-hr: 12-hr LD cycle, then drinking activity was recorded in constant darkness. The order of testing was reversed in a second group of mice. So that every animal served as its own control, $\Delta \tau$ for each mouse was calculated by subtracting each animal's $\tau_{\mathrm{DD}}$ for the locomotor rhythm from its $\tau_{\mathrm{DD}}$ for the drinking rhythm. For most mice, whatever the order of testing, $\Delta \tau$ had a positive value; that is, $\tau_{\mathrm{DD} \text { (drinking) }}$ was longer than $\tau_{\mathrm{DD} \text { (locomotion) }}$ (Fig. 6). This discrepancy appeared more marked, with much greater variability, in BALB/c mice; the range of $\Delta \tau$ values was $0.51 \mathrm{hr}$ (nearly $31 \mathrm{~min}$ ) in BALB/c mice but only $0.11 \mathrm{hr}$ (less than 7 $\mathrm{min}$ ) in C57BL/6 mice. The most extreme case was a $\mathrm{BALB} / \mathrm{c}$ mouse with a $\tau_{\mathrm{DD} \text { (locomotion) }}$ of $23.02 \mathrm{hr}$ but a $\tau_{\mathrm{DD} \text { (drinking) }}$ of 23.54

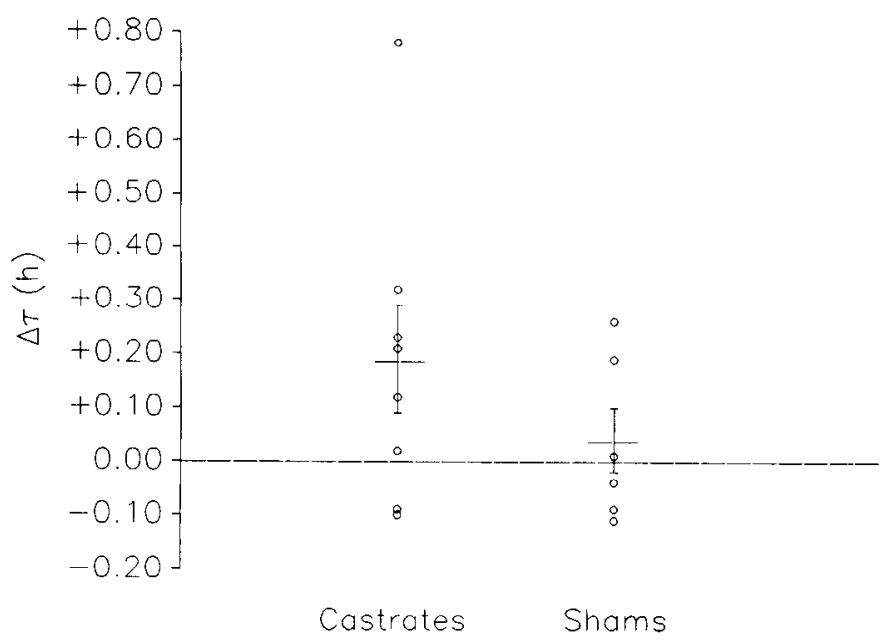

Figure 5. $\Delta \tau\left(\tau_{\mathrm{DD}}\right.$ after surgery $-\tau_{\mathrm{DD}}$ before surgery) for individual $\mathrm{BALB} / \mathrm{c}$ mice. See Results for details. 


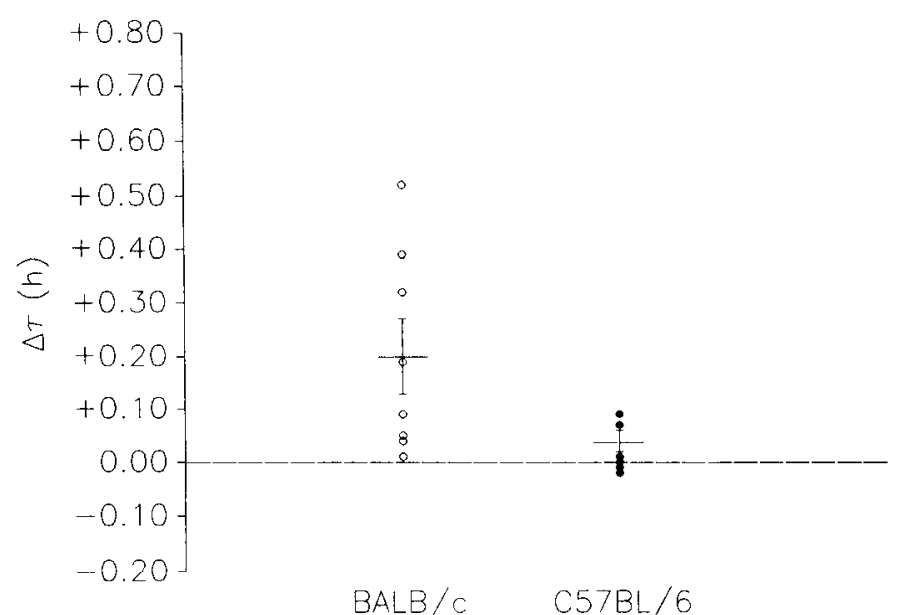

Figure 6. $\Delta \tau\left(\tau_{\mathrm{DD} \text { (drinking) }}-\tau_{\mathrm{DD} \text { (locomotion) }}\right)$ for individual $\mathrm{BALB} / \mathrm{c}$ and C57BL/6 mice. See Results for details.

hr. The mean $\Delta \tau$ for the BALB/c strain $(+0.20 \pm 0.07 \mathrm{hr}, n=$ 8) was significantly different from the mean $\Delta \tau$ for the C57BL/6 strain $[+0.04 \pm 0.02 \mathrm{hr}, n=8 ; p<0.05$ by ANOVA; $F=5.67$, $d f=(1,14)]$.

\section{On the mode of inheritance of the interstrain difference in mean $\tau_{D D}$}

Table 2 shows mean values of $\tau_{\mathrm{DD}}$ for locomotor rhythms in the reciprocal $F_{1}$ hybrids of $\mathrm{BALB} / \mathrm{c}$ and $\mathrm{C} 57 \mathrm{BL} / 6$ matings. All the values for the $\mathrm{F}_{1} \mathrm{~s}$ grossly resembled the C57BL/6 genotype. There was no overall effect of sex on mean $\tau_{\mathrm{DD}}[p=0.52$ by ANOVA; $F=0.43$, $d f=(1,30)]$, but there was a significant maternal effect, with the $\mathrm{CByB} \mathrm{F}_{1} \mathrm{~s}$ (offspring of $\mathrm{BALB} / \mathrm{c}$ mothers) exhibiting a shorter mean $\tau_{\mathrm{DD}}$ than the $\mathrm{B}^{6} \mathrm{CByF}_{1} \mathrm{~s}$ [offspring of C57BL/ 6 mothers; $p<0.001$ by ANOVA; $F=16.10, d f=$ $(1,30)]$. An ANOVA based on all 4 groups showed that the main effect of hybrid strain was significant $(p<0.001, F=17.22)$, but not the main effect of $\operatorname{sex}(p=0.41, F=0.69)$ nor the interaction between hybrid strain and $\operatorname{sex}(p=0.08, F=3.39)$.

Although it is likely that multiple genetic loci mediate the many interstrain differences in mean $\tau_{\mathrm{DD}}$ listed in Table 1 , a single locus may be responsible for the difference observed between any 2 strains (e.g., BALB/c and C57BL/6). One strategy to begin to assess this possibility makes use of RI strains (Bailey, 1981). These strains arc derived by crossing 2 alrcady cxisting inbred strains (the progenitor strains), then returning to brother $x$ sister inbreeding from the $\mathrm{F}_{2}$ generation onwards. The genome of each established RI strain is a replicable, homozygous mixture of the 2 progenitor genomes. When a trait that differs between 2 of the progenitors (e.g., $\tau_{\mathrm{DD}}$ ) is determined by a single genetic

Table 2. $\tau_{\mathrm{DD}}$ of reciprocal $F_{1}$ hybrids

\begin{tabular}{llll} 
Strain & Sex $^{a}$ & $n$ & Mean $\tau_{\text {DD }} \pm$ SEM \\
\hline CByB6F $_{1}$ & F & 8 & $23.72 \pm 0.02$ \\
& M & 8 & $23.63 \pm 0.05$ \\
B6CByF $_{1}$ & F & 8 & $23.80 \pm 0.02$ \\
& M & 8 & $23.84 \pm 0.03$
\end{tabular}

${ }^{a} \mathrm{~F}$, female; M, male.

\begin{tabular}{|c|c|c|}
\hline Strain & $n$ & Mean $\tau_{\mathrm{DD}} \pm$ SEM \\
\hline CXBD/By & 10 & $23.78 \pm 0.03$ \\
\hline $\mathrm{CXBE} / \mathrm{By}$ & 12 & $23.69 \pm 0.03$ \\
\hline $\mathrm{CXBG} / \mathrm{By}^{a}$ & 10 & $23.87 \pm 0.03$ \\
\hline $\mathrm{CXBH} / \mathrm{By}$ & 10 & $23.62 \pm 0.03$ \\
\hline $\mathrm{CXBI} / \mathrm{By}^{a}$ & 12 & $23.73 \pm 0.01$ \\
\hline $\mathrm{CXBJ} / \mathrm{By}$ & 6 & $23.78 \pm 0.04$ \\
\hline CXXK/By & 10 & $23.59 \pm 0.05$ \\
\hline
\end{tabular}

${ }^{a}$ Albino strains.

locus, an RI strain-distribution pattern emerges: one of the progenitors and approximately $1 / 2$ of the RI strains show one phenotype, while the second progenitor and the rest of the RI strains show the other phenotype. A polygenic mode of inheritance does not show this bimodal strain distribution pattern. Table 3 shows mean values of $\tau_{\mathrm{DD}}$ for locomotor rhythms in the $7 \mathrm{CXB}$ RI strains. Although these means were all relatively long (ranging from 23.59 to $23.87 \mathrm{hr}$ ) and superficially resembled the mean $\tau_{\mathrm{DD}}$ in the C57BL/6 progenitor strain, they were not a homogeneous group $[p<0.0001$ by ANOVA; $F=8.87, d f=(6,63)]$. A Student-Newman-Keuls test at the 0.05 level revealed that strains $\mathrm{K}$ and $\mathrm{H}$ were significantly different from strains $\mathrm{I}, \mathrm{J}, \mathrm{D}$, and $G$ and from $J, D$, and $G$, respectively, and that strain $G$ was significantly different from strains $\mathrm{K}, \mathrm{H}, \mathrm{E}$, and $\mathrm{I}$.

\section{Discussion}

The murine circadian timekeeping mechanism functions as an innate clock, its development genetically programmed independently of the environment (Davis and Menaker, 1981). The availability of inbred mouse strains that display robust, nonpathological differences in the properties of their circadian systems allows an assessment of the genetic contributions to clock function. Inbred strains are derived from multiple generations of brother $\times$ sister matings; individuals within a given strain are homozygous and genetically identical. Therefore, differences within strains suggest environmental influences or errors of measurement, whereas differences between strains imply genetic variation at loci affecting the trait of interest. Our data indicate that 1 or more genetic loci influence the value of $\tau$, as others have previously concluded (Ebihara et al., 1978; Possidente and Hegmann, 1980, 1982; Buttner and Wollnik, 1984; Ralph and Menaker, 1988; Peleg et al., 1989). The mean $\tau_{\mathrm{DD}}$ difference between the BALB/c and C57BL/6 strains of almost $1 \mathrm{hr}$ is a large difference, considering that $\tau$ cannot deviate too far from $24 \mathrm{hr}$ for the pacemaker to remain circadian. Indeed, even the harsh treatment of feeding mice heavy water elicits a $\tau$ change of little more than $1.5 \mathrm{hr}$ (Daan and Pittendrigh, 1976b).

Table 4 shows previously published $\tau$ 's for some of the inbred strains we surveyed; even though the studies differ in the substrains and recording techniques used, the measured $\tau$ 's in $\mathrm{BALB} / \mathrm{c}$ and $\mathrm{C} 57 \mathrm{BL} / 6$ mice in these reports also appear relatively short and long, respectively. On the other hand, Oliverio and associates reported that BALB/c mice do not show a "clearcut" circadian locomotor rhythm in constant darkness (quoted in Kempf et al., 1982). Rosenwasser (1990) has critiqued technical aspects of this work, and his examination of $5 \mathrm{BALB} / \mathrm{c}$ male mice instead disclosed activity rhythms that were present but markedly unstable. There were abrupt changes of $\tau$, disintegration of activity into ultradian periodicities, and apparent 
arhythmicity. We did not find such gross lability in our records; some of our BALB/c mice did not run well (most commonly by not running at all), but this was also true for mice of other strains (e.g., SEC/1ReJ). Although we did not study our animals for as long as Rosenwasser did (approximately $240 \mathrm{~d}$ ), the circadian disorganization he observed appeared unrelated to the length of time that the mice spent in free-running conditions. Because his subjects were obtained from a private breeding stock originally derived from the Jackson Laboratory's BALB/cJ strain, it is possible that genetic "drift" has led to differences between his BALB/c mice and ours. (We have now recorded locomotor rhythms in $6 \mathrm{BALB} / \mathrm{cJ}$ mice purchased from the Jackson Laboratory; 1 animal did not run, but the others expressed robust rhythms with a mean $\tau_{D D}$ of $23.12 \pm 0.19 \mathrm{hr}$.) Another difference was the continuous presence of dim red light (25-50 lux) during Rosenwasser's experiments; in addition, his mice cohabited with C57BL/ 6 females for intervals of 4-5 days while the study was in progress.

Our observation that the onset of locomotor activity in BALB/c and $\mathrm{C} 57 \mathrm{BL} / 6$ mice adopted a similar phase relationship to the LD cycle implies that an interstrain difference in PRC shape must compensate for the interstrain difference in mean $\tau_{\mathrm{DD}}$. On the basis of entrainment theory, we expected that either the value of $D$ in the BALB/c strain would be greater than its value in the C57BL/6 strain or (as in fact we found) the value of $A$ would be smaller. Our results on $\tau$ and PRC shape are in complete agreement with the work of Daan and Pittendrigh (1976a). These workers showed that $D-A$ has a positive value in the mouse (but a negative one in the hamster) and that the value of $D-A$ is larger (more positive) if $\tau$ is shorter. A decrease in $A$ was responsible for this effect in the mouse, whereas an increase in $D$ also occurred in the hamster (see also Puchalski and Lynch, 1988, for preferential changes of $D$ in hamsters). Thus, our data indicate that the correlation between $\tau$ and PRC shape holds not only for comparisons between species and between individuals within a species (Daan and Pittendrigh, 1976a), but also for comparisons between 2 inbred strains of a species.

Our next set of experiments on the strains investigated the possible influence of factors that are known to modify the value of $\tau$ in rodents. One such factor is the history of previous light exposure (Pittendrigh and Daan, 1976a). Although such aftereffects of light only temporarily influence $\tau$ in pigmented mice (Davis and Menaker, 1981; but not in cockroaches: see Barrett and Page, 1989), we were concerned that the albinism of BALB/c mice might have altered their light perception in some way (Possidente et al., 1982). Nonetheless, our data indicate that the interstrain difference in mean $\tau_{\mathrm{DD}}$ remained unchanged even in mice that were never exposed to environmental light. Parenthetically, our survey (Table 1) revealed no obvious relationship between albinism and mean $\tau_{\mathrm{DD}} ; 129 / \mathrm{J}, \mathrm{RF} / \mathrm{J}, \mathrm{SWR} / \mathrm{J}, \mathrm{AKR} / \mathrm{J}$, $\mathrm{A} / \mathrm{J}$, and $\mathrm{BALB} / \mathrm{cByJ}$ are all albino strains.

Our data also indicate that the interstrain difference in mean $\tau_{\mathrm{DD}}$ did not depend on the higher circulating levels of testosterone found in BALB/c mice (Batty, 1978; Melanitou et al., 1987). Castrated male mice have been reported to show longer $\tau$ 's than sham-operated animals (Daan et al., 1975), but this finding was partially due to a postsurgical shortening of $\tau$ in the shams, which orchiectomy prevented. Castrated male hamsters do not show longer $\tau$ 's (Morin and Cummings, 1981; Davis et al., 1983). Additional evidence that circulating testosterone levels alone did not account for interstrain mean $\tau_{D D}$ differences comes from our survey (Table 1); while testosterone concentrations in BALB/c
Table 4. Published $\tau$ of inbred mouse strains

\begin{tabular}{llll} 
Str a & $\tau_{\mathrm{DD}}{ }^{a}$ & $\tau^{b}$ & Reference \\
\hline C57BL/6 & 23.77 & 23.59 & Ebihara et al., 1978 \\
& & 23.73 & Possidente and Stephan, 1988 \\
& & $23.28^{c}$ & Ebihara et al., 1988b \\
& & $23.52^{d}$ & Abe et al., 1989 \\
AKR/J & 23.52 & $23.5^{d}$ & Possidente et al., 1982 \\
DBA/2J & 23.46 & 23.31 & Possidente and Stephan, 1988 \\
C57BL/10 & 23.43 & 23.47 & Ebihara et al., 1978 \\
& & $23.9^{d}$ & Possidente et al., 1982 \\
& & 23.5 & Welsh et al., 1986 \\
& & 23.30 & Possidente and Stephan, 1988 \\
A/J & 23.37 & $22.9^{d}$ & Possidente et al., 1982 \\
BALB/c & 22.94 & $23.4^{c}$ & Haus et al., 1967 \\
& & $22.7^{d}$ & Possidente et al., 1982 \\
& & $22.9^{\circ}$ & Possidente and Stephan, 1988
\end{tabular}

a Values taken from the present study.

"Valucs taken from previous studies.

c Value of $\tau$ obtained in blinded mice.

${ }^{d}$ Value of $\tau$ obtained in mice maintained in constant dim red light.

mice are twice those in C57BL/6 mice (Batty, 1978), testosterone concentrations in $129 / \mathrm{J}$ and $\mathrm{RF} / \mathrm{J}$ mice (with the longest mean $\tau_{\mathrm{DD}} \mathrm{S}$ we measured) are reported to be approximately 8 times higher (Melanitou et al., 1987). Thyroxine concentrations are also higher in BALB/c than in C57BL mice $(7.4 \pm 0.5 \mu \mathrm{g} /$ ml vs $5.2 \pm 0.4 \mu \mathrm{g} / \mathrm{ml}$; Stewart et al., 1978), but this difference is unlikely to be important in the determination of $\tau$ (Morin, 1988).

Finally, we recorded circadian rhythms of drinking activity in the 2 strains because there have been reports that access to a running wheel yields measurements of $\tau$ shorter than measurements based on other activity rhythms recorded in the same animals housed in cages without wheels [e.g., rhythms of burrow emergence (Pratt and Goldman, 1986), drinking (Yamada et al., 1986), and movement in the cage (Yamada ct al., 1988)]. Because the act of running in a wheel seems to affect circadian timekeeping in rodents (for review, see Mrosovsky et al., 1989), we were concerned that the relatively short mean $\tau_{\mathrm{DD}}$ in BALB/c mice might have been due in some way to their "hyperemotionality" (Thompson, 1953) and possibly greater activity (Lassalle and Le Pape, 1978; Beau, 1986) in the running wheel than C57BL/6 mice. However, because the mean $\tau_{\mathrm{DD} \text { (drinking) }}$ in $\mathrm{BALB} / \mathrm{c}$ mice was $0.20 \mathrm{hr}(12 \mathrm{~min})$ longer than the mean $\tau_{\mathrm{DD}}$ (locomotion), the 50 -min interstrain difference in mean $\tau_{\mathrm{DD}}$ cannot be attributed entirely to a differential effect of the running wheel on the BALB/c strain. Nevertheless, the putative "feedback" of an expressed circadian rhythm to its pacemaker merits further study; the BALB/c strain may be a useful model for investigation of the running wheel's apparent ability to accelerate the pacemaker's endogenous oscillation. In BALB/c mice, the discrepancy between the measurement of $\tau_{\mathrm{DD}}$ based on drinking and that based on locomotion varied widely among individual mice (from 0.6 to $31 \mathrm{~min}$ ); in individual C57BL/6 mice, the measured $\tau_{\mathrm{nn}} \mathrm{s}$ for drinking and locomotion were in no case different by much more than $5 \mathrm{~min}$. Although our results were no different if we reversed the order of testing of the 2 circadian rhythms, our next task will be to assess more systematically spontaneous changes in $\tau_{\mathrm{DD}}$ over time by long-term recordings in BALB/c mice (Rosenwasser, 1990). We must also address the possibility that 
drinking and locomotor rhythms express different $\tau_{\mathrm{DD}} \mathrm{s}$ simultaneously, that is, that the rhythms might be internally desvnchronized in individual BALB/c mice. Further work using a different type of cage and recording setup will be required to resolve this issue; however, drinking and locomotor rhythms are normally synchronized in rodents (Shibuya et al., 1980), and we are aware of no precedent for internal desynchronization of circadian rhythms in mice (Haus et al., 1967; Richardson et al., 1985; Welsh et al., 1985).

Further work will also be required to determine the mode of inheritance of the interstrain difference in mean $\tau_{\mathrm{DD}}$. Examination of reciprocal $F_{1}$ hybrids can reveal dominance effects, sex linkage, and maternal influences transmitted to progeny in utero and during postnatal development. Although the C57BL/6 genotype was dominant in our cross, it is important to note that an allele dominant in a given hybrid combination may be recessive in another (e.g., in the cross between the C57BL/6 and DBA/2J strains; Possidente and Stephan, 1988). As previously reported in mice (Possidente and Stephan, 1988), we found no effect of sex on the mean value of $\tau_{\mathrm{DD}}$. On the other hand, we did find a statistically significant maternal influence, though its amount $(0.14 \mathrm{hr}$ ) was small (i.e., on the order of $8 \mathrm{~min}$ ). Possidente and Stephan (1988) noted a suggestive (but statistically insignificant) maternal effect on the value of $\tau_{\mathrm{DD}}$ in the reciprocal $\mathrm{F}_{1} \mathrm{~s}$ of a cross between the C57BL/6 and DBA/2J strains, but they found no effect when C57BL/10Sn and BALB/c mice were crossed. Similarly, crosses between wild-type hamsters and those homozygous and heterozygous for the tau mutation produce offspring with altered $\tau$ 's that are unaffected by their mother's phenotype (Ralph and Menaker, 1988). Furthermore, crosses between inbred strains that differ in parameters describing their expressed circadian rhythms entrained to the LD cycle (e.g., phase and amplitude) yield reciprocal $F_{1}$ hybrids that do not differ in these parameters (e.g., LD-entrained rhythms of glyceraldehyde-3-phosphate dehydrogenase activity of the thymus in $\mathrm{C} 57 \mathrm{BL} / 6 \times \mathrm{A} / \mathrm{J}$ mice: Peleg et al., 1982; body temperature in C57BL/6 $\times \mathrm{C} 3 \mathrm{H} / 2 \mathrm{Ibg}$ mice: Connolly and Lynch, 1983; locomotion in $\mathrm{LEW} / \mathrm{Ztm} \times \mathrm{ACI} / \mathrm{Ztm}$ rats: Wollnik et al., 1987; locomotion in C57BL/6 $\times$ BALB/c mice: Beau, 1988). Of interest, in 2 species of wild mice (Mus booduga and Acomys cahirinus), the role of the mothers in organizing their pups' circadian rhythmicity differs and may depend on whether the species is altricial or precocious in its development (Viswanathan and Chandrashekaran, 1985; Weaver and Reppert, 1987). Considering the magnitude of the effect we found, it will be important to record circadian drinking rhythms in our CByB6 and $\mathrm{B} 6 \mathrm{CBy}$ reciprocal $F_{1}$ hybrids.

The number of genetic loci responsible for the interstrain difference in mean $\tau_{\mathrm{DD}}$ may be difficult to establish. Classical crosses (reciprocal $F_{1}, F_{2}$, and backcross generations) can be constructed to determine whether $\tau_{\mathrm{DD}}$ segregation patterns conform to the expected Mendelian ratios for single-gene inheritance, but such a breeding strategy is a major undertaking and may yield distorted estimates of heritability when inbred strains are crossed (Whitney et al., 1970). In addition to these considerations, we examined the CXB RI strains as our initial step for another reason; namely, if we could implicate a single locus, then the RI strain-distribution pattern for $\tau_{\mathrm{DD}}$ could be compared to the patterns for known loci whose chromosomal locations have been mapped. Unfortunately, interpretation of the pattern we found (i.e., that all the recombinant phenotypes resembled the C57BL/6 progenitor strain) is ambiguous, though a similar RI strain-distribution pattern has been reported for the variation in size of the $H i n c I I$ and $P s t I$ restriction fragments, which hybridize to probes for 2 closely linked regions (the Fis- 1 and Int-2 sites, respectively) on mouse chromosome 7 (Silver and Buckler, 1986). Importantly, our analysis using a multiple range test suggests that the recombinant strains are statistically separable into more than 1 phenotypic group. Thus, though the small number of available CXB RI strains limits the confidence with which conclusions can be made, our data provide no support for the hypothesis that the interstrain difference in mean $\tau_{\mathrm{DD}}$ is monogenically inherited. Beau (1988) reached a similar conclusion for the inheritance of several parameters describing LD-entrained locomotor rhythmicity in these strains.

In any case, whatever their genetic basis, inbred strain differences offer a promising noninvasive experimental tool for investigation of the neurobiological substrates of circadian rhythmicity (see, e.g., Hotz et al., 1987; Abe et al., 1989). Of particular interest have been recent studies exploring the response of the circadian systems of $\mathrm{C} 57 \mathrm{BL} / 6$ and $\mathrm{SK} / \mathrm{Nga}$ mice to agents that affect GABA neurotransmission (Ebihara et al., $1988 a, b)$. GABA is the most plentiful substance identified in SCN axons and boutons (van den Pol and Gorcs, 1986) and is believed to modulate light-induced phase shifts of rodent circadian rhythms in a phase-dependent manner (i.e., the regulation of phase delays and phase advances appears to be regulated differently; Ralph and Menaker, 1989). It is noteworthy that several indices of GABA activity in the BALB/c and C57BL/6 strains show large differences: whole-brain glutamic acid decarboxylase activity is highest in BALB/c and lowest in C57BL/6 mice (of 7 strains tested; Tunnicliff et al., 1973), whole-brain ${ }^{3} \mathrm{H}$-diazepam binding is lowest in BALB/c and nearly the highest in C57BL/6 mice (of 4 strains tested; Robertson, 1979), and an exploratory behavioral response to diazepam is lowest in BALB/c and second-highest in C57BL/6 mice (of 5 strains tested; Crawley and Davis, 1982). Therefore, pharmacological studies using $\mathrm{BALB} / \mathrm{c}$ and $\mathrm{C} 57 \mathrm{BL} / 6$ mice may help to illuminate the circadian functions of GABA and to elucidate its possible role in determining $\tau$, PRC shape, and wheel-running behavior.

\section{References}

Abe H, Kida M, Tsuji K, Mano T (1989) Feeding cycles entrain circadian rhythms of locomotor activity in CS mice but not in C57BL/ 6J mice. Physiol Behav 45:397-401.

Aguilar-Roblero R, Garcia-Hernandez F, Aguilar R, Arankowsky-Sandoval G, Drucker-Colin R (1986) Suprachiasmatic nucleus transplants function as an endogenous oscillator only in constant darkness. Neurosci Lett 69:47-52.

Aschoff J, ed (1981) Handbook of behavioral neurobiology, vol 4, biological rhythms. New York: Plenum.

Bailey DW (1981) Recombinant inbred strains and bilineal congenic strains. In: The mouse in biomedical research, vol 1, history, genetics, and wild mice (Foster HL, Small JD, Fox JG, eds), pp 223-239. New York: Academic.

Barrett RK, Page TL (1989) Effects of light on circadian pacemaker development. I. The freerunning period. J Comp Physiol [A] 165:4149.

Batty J (1978) Plasma levels of testosterone and male sexual behavior in strains of the house mouse (Mus musculus). Animal Behav 26: $339-348$.

Beau J (1986) Components comparison of activity rhythm in three inbred mice strains. In: Genetic approaches to behavior (Medioni J, Vaysse G, eds), pp 19-27. Toulouse: Privat I.E.C.

Beau J (1988) Mise en évidence de corrélats polygéniques des caractéristiques du rythme de l'activité chez un Mammifère: étude de deux lignées de souris consanguines C57BL/6By et BALB/cBy. C R Acad Sci Paris 307:37-40. 
Büttner D, Wollnik F (1984) Strain-differentiated circadian and ultradian rhythms in locomotor activity of the laboratory rat. Behav Genet 14:137-152.

Connolly MS, Lynch CB (1981) Circadian variation of strain differences in body temperature and activity in mice. Physiol Behav 27: 1045-1049.

Connolly MS, Lynch CB (1983) Classical genetic analysis of circadian body temperature rhythms in mice. Behav Genet 13:491-500.

Crawley JN, Davis LG (1982) Baseline exploratory activity predicts anxiolytic responsiveness to diazepam in five mouse strains. Brain Res Bull 8:609-612.

Daan S, Pittendrigh CS (1976a) A functional analysis of circadian pacemakers in nocturnal rodents. II. The variability of phase response curves. J Comp Physiol [A] 106:253-266.

Daan S, Pittendrigh CS (1976b) A functional analysis of circadian pacemakers in nocturnal rodents. III. Heavy water and constant light: homeostasis of frequency? J Comp Physiol [A] 106:267-290.

Daan S, Damassa D, Pittendrigh CS, Smith ER (1975) An effect of castration and testosterone replacement on a circadian pacemaker in mice (Mus musculus). Proc Natl Acad Sci USA 72:3744-3747.

Davis FC, Menaker M (1981) Development of the mouse circadian pacemaker: independence from environmental cycles. J Comp Physiol [A] 143:527-539.

Davis FC, Darrow JM, Menaker M (1983) Sex differences in the circadian control of hamster wheel-running activity. Am J Physiol 244:R93-R105.

DeCoursey PJ, Buggy J (1989) Circadian rhythmicity after neural transplant to hamster third ventricle: specificity of suprachiasmatic nuclei. Brain Res 500:263-275.

Earnest DJ, Sladek CD (1986) Circadian rhythms of vasopressin release from individual rat suprachiasmatic explants in vitro. Brain Res 382:129-133.

Earnest DJ, Turek FW (1985) Neurochemical basis for the photic control of circadian rhythms and seasonal reproductive cycles: role for acetylcholine. Proc Natl Acad Sci USA 82:4277-4281.

Earnest DJ, Sladek CD, Gash DM, Wiegand SJ (1989) Specificity of circadian function in transplants of the fetal suprachiasmatic nucleus. J Neurosci 9:2671-2677.

Ebihara S, Tsuji K, Kondo K (1978) Strain differences of the mouse's free-running circadian rhythm in continuous darkness. Physiol Behav 20:795-799.

Ebihara S, Hudson DJ, Marks T, Menaker M (1987) Pineal indole metabolism in the mouse. Brain Res 416:136-140.

Ebihara S, Goto M, Oshima I (1988a) The phase-shifting effects of pentobarbital on the circadian rhythm of locomotor activity in the mouse: strain differences. Brain Res 454:404-407.

Ebihara S, Goto M, Oshima I (1988b) Different responses of the circadian system to GABA-active drugs in two strains of mice. J Biol Rhythms 3:357-364.

Foster HL, Small JD, Fox JG, eds (1982) The mouse in biomedical research, vol IV, experimental biology and oncology. New York: Academic.

Gattermann VR, Hilbig H, Winkelmann E (1987) On the circadian rhythms in blind microphthalmic mice. Z Versuchstierkd 30:143146.

Green DJ, Gillette R (1982) Circadian rhythm of firing rate recorded from single cells in the rat suprachiasmatic brain slice. Brain Res 245 198-200.

Haus E, Lakatua D, Halberg F (1967) The internal timing of several circadian rhythms in the blinded mouse. Exp Med Surg 25:7-45.

Hall JC, Rosbash M (1987) Genetic and molecular analysis of biological rhythms. J Biol Rhythms 2:153-178.

Hotz MM, Connolly MS, Lynch CB (1987) Adaptation to daily mealtiming and its effect on circadian temperature rhythms in two inbred strains of mice. Behav Genet 17:37-51.

Ibuka N (1987) Circadian rhythms in sleep-wakefulness and wheelrunning activity in a congenitally anophthalmic rat mutant. Physiol Behav 39:321-326.

Inouye ST, Kawamura H (1979) Persistence of circadian rhythmicity in a mammalian hypothalamic "island" containing the suprachiasmatic nucleus. Proc Natl Acad Sci USA 76:5962-5966.

Kempf E, Mandel P, Oliverio A, Puglisi-Allegra S (1982) Circadian variations of noradrenaline, 5 -hydroxytryptamine and dopamine in specific brain areas of $\mathrm{C} 57 \mathrm{BL} / 6$ and $\mathrm{BALB} / \mathrm{c}$ mice. Brain Res 232: $472-478$.
Lassalle JM, Le Pape G (1978) Locomotor activity of two inbred strains of mice in a seminatural and a breeding cage environment. Behav Genet 8:371-376.

Lehman MN, Silver R, Gladstone WR, Kahn RM, Gibson M, Bittman EL (1987) Circadian rhythmicity restored by neural transplant. Immunocytochemical characterization of the graft and its integration with the host brain. J Neurosci 7:1626-1638.

Meijer JH, Rietveld WJ (1989) Neurophysiology of the suprachiasmatic circadian pacemaker in rodents. Physiol Rev 69:671-707.

Melanitou E, Cohn DA, Bardin CW, Janne OA (1987) Genetic variation in androgen regulation of ornithine decarboxylase gene expression in inbred strains of mice. Mol Endocrinol 1:266-273.

Moore RY (1981) The suprachiasmatic nucleus, circadian rhythms, and regulation of brain peptides. In: Neurosecretion and brain peptides (Martin JB, Reichlin S, Bick K, eds), pp 449-458. New York: Raven.

Morin LP (1988) Propylthiouracil, but not other antithyroid treatments, lengthens hamster circadian period. Am J Physiol 255:R1-R5.

Morin LP, Cummings LA (1981) Effect of surgical or photoperiodic castration, testosterone replacement or pinealectomy on male hamster running rhythmicity. Physiol Behav 26:825-838.

Mrosovsky N, Reebs SG, Honrado GI, Salmon PA (1989) Behavioral entrainment of circadian rhythms. Experientia 45:696-702.

Newman GC, Hospod FE (1986) Rhythm of suprachiasmatic nucleus 2-deoxyglucose uptake in vitro. Brain Res 381:345-350.

Noguchi T, Sugisaki T, Kudo M, Satoh I (1986) Retarded growth of the suprachiasmatic nucleus and pineal body in $d w$ and lit dwarf mice. Dev Brain Res 26:161-172.

Oliverio A, Malorni W (1979) Wheel running and sleep in two strains of mice: plasticity and rigidity in the expression of circadian rhythmicity. Brain Res 163:121-133.

Peleg L, Nesbitt MN, Ashkenazi IE (1982) A strain difference in the daily rhythm of glyceraldehyde-3-phosphate dehydrogenase activity in the mouse. J Comp Physiol [B] 148:137-142.

Peleg L, Nesbitt MN, Ashkenazi IE (1989) Strain dependent response of circadian rhythms during exposure to continuous illumination. Life Sci 44:893-900.

Pittendrigh CS, Daan S (1976a) A functional analysis of circadian pacemakers in nocturnal rodents. I. The stability and lability of spontaneous frequency. J Comp Physiol [A] 106:223-252.

Pittendrigh CS, Daan S (1976b) A functional analysis of circadian pacemakers in nocturnal rodents. IV. Entrainment: pacemaker as clock. J Comp Physiol [A] 106:291 - 331.

Possidente B, Hegmann JP (1980) Circadian complexes: circadian rhythms under common gene control. J Comp Physiol [B] 139:121125.

Possidente B, Hegmann JP (1982) Gene differences modify Aschoff's rule in mice. Physiol Behav 28:199-200.

Possidente B, Stephan FK (1988) Circadian period in mice: analysis of genetic and maternal contributions to inbred strain differences. Behav Genet 18:109-117.

Possidente B, Hegmann JP, Carlson L, Elder B (1982) Pigment mutations associated with altered circadian rhythms in mice. Physiol Behav 28:389-392.

Pratt BL, Goldman BD (1986) Environmental influences upon circadian periodicity of Syrian hamsters. Physiol Behav 36:91-95.

Puchalski W, Lynch GR (1988) Characterization of circadian function in Djungarian hamsters insensitive to short day photoperiod. J Comp Physiol [A] 162:309-316.

Ralph MR, Menaker M (1988) A mutation of the circadian system in golden hamsters. Science 241:1225-1227.

Ralph MR, Menaker M (1989) GABA regulation of circadian responses to light. I. Involvement of $\mathrm{GABA}_{\mathrm{A}}$-benzodiazepine and $\mathrm{GABA}_{\mathrm{B}}$ receptors. J Neurosci 9:2858-2865.

Ralph MR, Foster RG, Davis FC, Menaker M (1990) Transplanted suprachiasmatic nucleus determines circadian period. Science 247: 975-978.

Richardson GS, Moore-Ede MC, Czeisler CA, Dement WC (1985) Circadian rhythms of sleep and wakefulness in mice: analysis using long-term automated recording of sleep. Am J Physiol 248:R320 R330.

Richter CP (1971) Inborn nature of the rat's 24-hour clock. J Comp Physiol Psychol 75:1-4.

Robertson HA (1979) Benzodiazepine receptors in"emotional" and 
"non-emotional" mice: comparison of four strains. Eur J Pharmacol 56:163-166.

Rosenwasser AM (1990) Circadian activity rhythms in BALB/c mice: a weakly-coupled circadian system? J Interdiscipl Cycle Res 21:9196.

Rusak B, Groos G (1982) Suprachiasmatic stimulation phase-shifts rodent circadian rhythms. Science 215:1407-1409.

Sawaki Y, Nihonmatsu I, Kawamura H (1984) Transplantation of the neonatal suprachiasmatic nuclei into rats with complete bilateral suprachiasmatic lesions. Neurosci Res 1:67-72.

Scheuch GC, Johnson W, Conner RL, Silver J (1982) Investigation of circadian rhythms in a genetically anophthalmic mouse strain: correlation of activity patterns with suprachiasmatic nuclei hypogenesis. J Comp Physiol [A] 149:333-338.

Schwartz WJ, Reppert SM (1985) Neural regulation of the circadian vasopressin rhythm in cerebrospinal fluid: a pre-eminent role for the suprachiasmatic nuclei. J Neurosci 5:2771-2778.

Schwartz WJ, Davidsen LC, Smith CB (1980) In vivo metabolic activity of a putative circadian oscillator, the rat suprachiasmatic nucleus. J Comp Neurol 189:157-167.

Shibata S, Oomura Y, Kita H, Hattori K (1982) Circadian rhythmic changes of neuronal activity in the suprachiasmatic nucleus of the rat hypothalamic slice. Brain Res 247:154-158.

Shibuya CA, Melnyk RB, Mrosovsky N (1980) Simultaneous splitting of drinking and locomotor activity rhythms in a golden hamster. Naturwissenschaften 67:45-46.

Silver J, Buckler CE (1986) A preferred region for integration of Friend murine leukemia virus in hematopoietic neoplasms is closely linked to the Int-2 oncogene. J Virol 60:1156-1158.

Stewart AD, Batty J, Harkiss GD (1978) Genetic variation in plasma thyroxine levels and minimal metabolic rates of the mouse, Mus musculus. Genet Res 31:303-306.

Thompson WR (1953) The inheritance of behavior: behavioral differences in fifteen mouse strains. Can J Psychol 7:145-155.

Tunnicliff G, Wimer CC, Wimer RE (1973) Relationships between neurotransmitter metabolism and behavior in seven inbred strains of mice. Brain Res 61:428-434.

van den Pol AN, Gorcs T (1986) Synaptic relationships between neurons containing vasopressin, gastrin-releasing peptide, vasoactive intestinal polypeptide, and glutamate decarboxylase immunoreactivity in the suprachiasmatic nucleus: dual ultrastructural immunocytochemistry with gold-substituted silver peroxidase. J Comp Neurol 252:507-521.

Viswanathan N, Chandrashekaran MK (1985) Cycles of presence and absence of mother mouse entrain the circadian clock of pups. Nature 317:530-531.

Weaver DR, Reppert SM (1987) Maternal-fetal communication of circadian phase in a precocious rodent, the spiny mouse. Am J Physiol 253:E401-E409.

Welsh DK, Richardson GS, Dement WC (1985) A circadian rhythm of hippocampal theta activity in the mouse. Physiol Behav 35:533538.

Welsh DK, Engel EMRA, Richardson GS, Dement WC (1986) Precision of circadian wake and activity onset timing in the mouse. $J$ Comp Physiol [A] 158:827-834.

Whitney G, McClearn GE, DeFries JC (1970) Heritability of alcohol preference in laboratory mice and rats. J Hered 61:165-169.

Wollnik F, Gärtner K, Büttner D (1987) Genetic analysis of circadian and ultradian locomotor activity rhythms in laboratory rats. Behav Genet 17:167-178.

Yamada N, Shimoda K, Takahashi K, Takahashi S (1986) Change in period of free-running rhythms determined by two different tools in blinded rats. Physiol Behav 36:357-362.

Yamada N, Shimoda K, Ohi K, Takahashi S, Takahashi K (1988) Free-access to a running wheel shortens the period of free-running rhythm in blinded rats. Physiol Behav 42:87-91.

Zatz M, Herkenham MA (1981) Intraventricular carbachol mimics the phase-shifting effect of light on the circadian rhythm of wheelrunning activity. Brain Res 212:234-238. 